$50-55^{\circ}$ Brix is registered, and this unstable syrup is then preserved with 200-300 parts per million of sulphur dioxide in the form of potassium metabisulphite. The present syrups are intended for use primarily with milk, and it is necessary to avoid an excessively sweet product as this detracts not only from the milk flavour, but also tends to mask the fresh flavour of the fruit. The question of curdling is not serious until any addition of acid is carried out. Even with the highly acid juices of the loganberry and blackcurrant there is very little fear of curdling when the normal concentrations, which are generally acepted in the milk bars, are used. A further process of interest is the adaptation of the carefully controlled fermentation in the fruit. This fermentation is effective first in completely disintegrating the cells which thus yield a richer, sweeter juice and, secondly, in decomposing a certain amount of pectin which would otherwise be deposited in the filtered product. Remarkable results have recently been obtained by the use of pectin-decomposing enzymes in which an addition of 0.2 per cent of enzyme has reduced the calcium pectate content of the juice from 0.134 per cent to a mere trace.

\section{The Kauri}

A SMALL pamphlet, Leaflet No. 26, on "The Properties and Uses of Kauri", Agathis australis, by A. R. Entrican, has been issued (Government Printer, Wellington, N.Z., 1935). This timber is one of the most useful of the coniferous softwoods, and has been known in international trade for more than a century. The kauri is the monarch of the New Zealand forests, dwarfing all other species. The bole in mature trees has singularly little taper; thus, although it does not attain the height of the North American redwoods (Sequoia) and the Australian eucalypts, it ranks among the largest timber-producing species in the world. It is said that in yielding flawless timber of exceptionally large size, the tree is unsurpassed by any other known species. The extensive virgin forests of the early European occupation have been severely depleted, but it is of good hope for the future to hear that the remaining stands are being placed under a system of forest regulations whereby a sustained yield of this valuable softwood will be assured. Owing to its evenness of texture and ease of working, to its small shrinkage powers, medium density and excellent strength properties and high durability, the timber is able to meet the most exacting requirements. It is made use of in all classes of building and general construction, in shipbuilding, car and wagon construction, tank and vat manufacture, military bridging, and the production of dairy and agricultural machinery and so forth. It is not surprising, as has been the case with fine species in other countries, that the brunt of the fellings for ordinary utilization by the increasing population of the country fell upon this beautiful tree.

\section{The National Institute of Agricultural Botany}

AT the annual general meeting of fellows of the National Institute of Agricultural Botany at Cambridge on July 16, the chairman of the Council, Sir
Daniel Hall, in the course of his address, stated that one of the primary objects of the Institute is to serve as a medium for introducing new varieties of farm crops to the public. For this purpose its trials are organized so as to provide an accurate measure of the relative merits or de-merits of each variety tested. These trials extend over three years or more, in order to level out weather differences, and are carried out at six different centres in order to eliminate differences due to soil variations. The improvements already effected in the yield of cereals make it unlikely that any new variety will show a 20 per cent improvement upon the existing varieties. Improvements in the nature of 5-10 per cent are more prob. able, but even a 5 per cent improvement would make a considerable financial difference to farmers. Farming is never at a standstill, and the Institute meets the changing agricultural situation by extending the scope of its trials. Trials of picking peas and chicory are now being carried out, and it is hoped that useful information will be derived from them. The potato trials at Ormskirk have done much to check the spread of wart disease by the encouragement given to the introduction of new immune varieties. Sir Daniel went on to say that close co-operation with the seed trade would be beneficial to both bodies. In serving the farmers, the Institute also serves the best interests of the seed trade, which has the highest degree of confidence in the Official Seed Testing Station. This is testified by the fact that the number of samples tested by the Official Seed Testing Station is steadily increasing year by year, and nearly 30,000 samples have been tested in the current year. In conclusion Sir Daniel expressed concern at the shrinkage in the number of fellows of the Institute : he hopes the Institute will never become a purely bureaucratic body, reponsible only to the Government.

\section{Prevention of Tuberculosis}

Sir Kingsuey Wood, the Minister of Health, inaugurated the twenty-second annual conference of the National Association for the Prevention of Tuberculosis at the County Hall, London, on July 16. $\mathrm{He}$ stated that great progress has been made in the fight against tuberculosis. For the first time on record, the total number of deaths in England and Wales from all forms of tuberculosis fell in 1935 below 30,000 . The standardized death-rate from tuberculosis has fallen from 1,915 to 687 per million in less than forty years. This striking record of progress is due in the first place to remarkable improvements in methods of treatment. Much also is due to the example given by the establishment, as a result of greater knowledge and active propaganda, of voluntary sanatoria and dispensaries. It is significant that no sanatorium in the modern sense existed in Great Britain before 1898. Improved standards of living and hygiene, better housing, better nutrition, purer milk supply and general public health measures have played and will continue to play a considerable part in the attack upon this disease. But there are many opportunities for further advance. There is a great need for encouraging those who were suffering or 
suspected to be suffering from tuberculosis to take advantage at the earliest possible stage of the facilities provided for diagnosis and treatment. The importance also of eliminating tuberculous cattle from the herds of Great Britain is obviously very great. Bovine tuberculosis is responsible in Great Britain for a large number of deaths, probably more than 2,500 per annum, and for a still larger amount of serious illness. Much remains to be done before we can be satisfied that the whole of our milk supply is safe.

\section{British School of Archæology at Athens}

ON October 13, the British School of Archæology at Athens will celebrate the fiftieth anniversary of its foundation by holding at the Royal Academy of Arts, Burlington House, an exhibition to illustrate the discoveries in Greece and Crete which have resulted from the work of the School, together with a special exhibit devoted to the Minoan civilizations of Greece, and the excavations of the School's honorary student, Sir Arthur Evans, at Knossos, in which the School's architects took part. This exhibit is being prepared by Sir Arthur Evans himself, with facilities kindly given him by the Keeper and Visitors of the Ashmolean Museum. It is understood that the exhibition will be inaugurated by His Royal Highness the Duke of Kent, on October 13 at 3 p.m., and will be open to the public from Oetober 14 until November 14. In connexion with the jubilee of the School, it is proposed also to raise a special fund to enable the School to increase its staff, improve its library and accommodation, and provide for the needs of the graduate students who, in increasing numbers, are sent to Greece for advanced study by the universities.

\section{Indian Vital Statistics for 1933}

THE chief vital statistical figures for British India for 1933 are : (1) total births, 9,678,876, giving a crude birth-rate of 35.5 per mille, (2) total deaths numbered $6,096,787$, giving a crude death-rate of $22 \cdot 4$ per mille, (3) infantile deaths numbered $1,650,973$, an infantile death-rate per 1,000 births of $170 \cdot 5$ (Ann. Rep. of the Public Health Commissioner with the Government of India for 1933. Government of India Press, New Delhi. Rs.6 as.4 or 10s.). The birthrate is more than double, the death-rate nearly double, and the infant mortality about two and a half times, the corresponding figures for England and Wales. It is remarked that, contrary to some recent statements, the population of India is increasing at an alarming rate, and by 1941 will probably reach 400 millions. The total land area of British India amounts to only $\mathbf{2 \cdot 4 4}$ acres per head of the population, but allowing for forest, uncultivated and fallow lands, only 0.72 acre per head is under food cropsquite insufficient for even the present population. Birth-control is viewed sympathetically, but only seven hundred medical women are available to instruct Indian women about it. Cholera deaths $(68,318)$ and plague deaths $(43,000)$ are not nearly so high as in some years, but smallpox deaths numbered 103,000, compared with 45,000 during the previous year-a disconcerting rise.

\section{Anti-Rabic Treatment in Southern India}

The Annual Report of the Director, Major Iyengar, of the Pasteur Institute of Southern India, Coonoor, states that during the year ended December 31, 1934, 414 persons underwent the complete, and 77 an incomplete, treatment at the Institute after bites by animals supposedly rabid. For the second time in the twenty-eight years of the Institute's existence, there were no deaths from hydrophobia among those treated. Paris fixed virus was in use in the form of Semple's carbolized five per cent sheep vaccine, and at the end of the year was in its 937 passage. The vaccine was also issued from several out-centres12,316 courses for nearly 13,000 cases, with 26 deaths from hydrophobia. In addition, anti-rabic vaccine was issued for the prophylactic treatment of 259 animals. In spite of what the Institute is doing, 412 deaths from hydrophobia were recorded in the Madras Presidency during 1934.

\section{Northern Lights}

Prof. Cart Størmer has directed attention to a prevalent confusion between the north magnetic pole and the point on the earth where the magnetic axis meets the surface. Thus, in the supplement to NATURE of May 16, 1936, it is stated on p. 813 that "It is the distance from the magnetic axis of the earth that counts, and that axis meets the surface of the earth at the north magnetic pole, which is in the island of Boothia in Canada" ; this should read as follows : "It is the distance from the magnetic axis of the earth that counts and that axis meets the surface of the earth about midway between the north magnetic pole and the north pole". This point is near NorthWestern Greenland, and it might be named the north axial pole. The zone or belt of greatest auroral display has this point for centre on the earth.

\section{The Night Sky in August}

THE nights during August are still rather short to afford much opportunity for a close serutiny of the rich fields about the galactic equator, which in the British Isles passes overhead from north-east to southwest about midnight at the beginning of the month. Even at nightfall, however, the sky is distinctive with Arcturus still fairly high towards the west : Jupiter a brilliant object in the south-west: Vega, Deneb and Altair not far from the meridian : Saturn rising with Pisces in the east, whilst Capella may be picked out towards the northern horizon. Full moon occurs on August $3^{\mathrm{d}} 3^{\mathrm{h}} 47^{\mathrm{m}}$ and new moon on August $17^{\mathrm{d}} 3^{\mathrm{h}} 21^{\mathrm{m}}$. The brightest star to be occulted this lunation is $\kappa$ Piscium (magnitude $4 \cdot 9$ ) - the reappearance may be observed on August $6^{\mathrm{d}} 1^{\mathrm{h}} 59 \cdot 7^{\mathrm{m}}$ (U.T.) at position angle $267^{\circ}$ from the north point of the lunar disk. Other occultations of stars, ranging in magnitude from $6 \cdot 3$ to $6 \cdot 7$, may be observed on August 5, 6, 10 and 13. Between August 9 and 12 occurs the maximum of the Perseid meteor shower, the radiant of which is in Perseus at R.A. $3^{\mathrm{h}} 0^{\mathrm{m}}$ and Dec. $57^{\circ} \mathrm{N}$. The meteors of this shower are yellowish in colour and move with medium velocity. The orbit of the shower is well determined and coincides with 